
\title{
$\angle S$ Research Square \\ Mass Screening Using Saliva Samples and Pooled Testing Strategy For SARS-CoV-2 RT-PCR Detection in Latvia
}

\section{Didzis Gavars ( $\sim$ didzis@egl.Iv )}

E. Gulbja Laboratory

\section{Mikus Gavars}

E. Gulbja Laboratory

\section{Dmitry Perminov}

E. Gulbja Laboratory

Janis Stasulans

E. Gulbja Laboratory

Justine Stana

E. Gulbja Laboratory

\section{Zane Metla}

E. Gulbja Laboratory

\section{Jana Pavare}

Children's Clinical University Hospital, Riga Stradins University

\section{Eriks Tauckels}

E. Gulbja Laboratory

\section{Uga Dumpis}

Pauls Stradins Clinical University Hospital

\section{Egils Gulbis}

E. Gulbja Laboratory

\section{Research Article}

Keywords: SARS-CoV-2, COVID-19, diagnostics, saliva, pooling

Posted Date: May 7th, 2021

DOI: https://doi.org/10.21203/rs.3.rs-468726/v1

License: (c) (i) This work is licensed under a Creative Commons Attribution 4.0 International License. Read Full License 


\section{Abstract}

\section{Background}

The number of COVID-19 cases is increasing globally and there is an urgency for a simple non-invasive method for the detection of SARS-CoV-2. Our study aimed to demonstrate that saliva can be used as a specimen for SARS-CoV2 detection notably for the screening of extensive population groups via pooling.

\section{Methods}

We performed 36 serial measurements of 8 SARS-CoV-2 positive saliva samples to confirm the stability of the specimen and completed 37 pools of saliva samples by adding one positive specimen per pool. We collected paired nasopharyngeal/oropharyngeal swabs (NPS) and saliva specimens and processed them within 24 hours of collection. To demonstrate that saliva is an appropriate specimen for SARS-CoV-2 detection a field study including 3,660 participants was performed between September 29 and October 1, 2020. A new solution for distribution and collection of self-sampled saliva was designed, produced and installed. All methods were performed in accordance with the relevant guidelines and regulations.

\section{Results}

Saliva specimens were stable for testing for up to 24 hours. The results of saliva samples were consistent with those obtained from NPS from the same patient with $90 \%$ sensitivity $(95 \% \mathrm{Cl} 68.3 \%-98.7 \%)$ and $100 \%$ specificity during the first two weeks after the onset of symptoms. Using pooling strategy 796 RT-PCR tests were performed. All pools showed $100 \%$ positivity in different pooling proportions. Overall, 44 saliva samples $(1.2 \%)$ tested positive for SARSCoV-2 during the field study. In total, between September 29 and April 10, 415673 RT-PCR saliva tests were performed. The contactless self-service terminals were placed in hospitals, factories and municipalities as an additional way to submit self-collected saliva for testing.

\section{Conclusion}

Our findings demonstrate that saliva is an appropriate specimen for pooling and SARS-CoV-2 screening with accurate diagnostic performance. Patient-performed simple specimen collection allows testing an extensive number of people rapidly, obtaining results of the spread of SARS-CoV-2 and allowing authorities to take timely measures. Automated sample distribution and collection points are accessible 24/7 allowing safe, contactless and more efficient way to submit various kind of samples for testing.

\section{Introduction}

Since the beginning of 2020 massive resources have been dedicated to control and mitigate the COVID-19 pandemic. Testing capacity and accessibility are crucial in monitoring COVID-19 outbreaks and allowing for the adjustment of measures put into place to reduce community transmission [1].

Viral nucleic acid detection using the real-time polymerase chain reaction (RT-PCR) assay remains the gold standard for the detection of SARS-CoV-2 and to diagnose COVID-19 [2]. Due to the increased demand for sampling and testing materials globally considerable constraints remain to conduct widespread screening for SARS-CoV- 2 .

Shortages of supplies and medical staff, logistical hurdles, as well the unpleasantness associated with obtaining a RT-PCR specimen making it difficult to practice the procedure on children and causing irritation for those who need 
to undergo repeated tests, all these factors have naturally accelerated research into alternative specimens and sampling methods for COVID-19 testing [3,4].

On September 21, 2020, Latvia had a 14-day cumulative number of COVID-19 cases of 5.1 per 100,000 people. By October 10 that number had risen to 66. During this period, laboratories experienced a significant overload [5]. Rapid and efficient solutions to increase testing capacity were needed.

The objective of this study was to confirm that saliva is a suitable specimen comparable to a nasopharyngeal/oropharyngeal swab for SARS-CoV-2 detection in specific populations. We also evaluated the pooling approach to employ it in field conditions for extensive screening of high-risk groups. Finally, a new solution was found for the distribution and collection of self-sampling kits for saliva testing. The new approach allows to increase sample collection capacity in a safe and effective way.

\section{Materials And Methods}

\section{Patient sample collection}

A single-center study was performed including all consented patients attending the laboratory for SARS-CoV-2 testing between May 12 and October 19, 2020. For the collection of the saliva samples, self-collection kits were distributed consisting of a specimen vial, registration form, alcohol pads for disinfection, and two safety plastic bags. Patients were requested to collect their saliva in an isolated location (keeping at least five meters distance from other persons or objects), preferably outdoors, at home, or in their car. The saliva was collected in a container without any additive and delivered to the laboratory within 24 hours. Paired nasopharyngeal/oropharyngeal swabs (NPS) for RT-PCR were collected using the standard method used in our laboratory [6].

Sample preparation and analysis using RT-PCR

Immediately upon arrival at the laboratory, the samples were pretreated by adding $1 \mathrm{ml}$ of phosphate-buffered saline (PBS). The extraction of RNA and RT-PCR testing was identical for both swab and pre-treated saliva samples. Viral RNA was extracted with standard commercial extraction methods (QIAGEN, Germany and LifeRiver, China) used in our laboratory. RT-PCR was performed using our laboratory-developed and validated test method which detects $S$ and $\mathrm{N}$ genes of the SARS-CoV-2 virus. Our validated and verified limit of detection $\left(\operatorname{LOD}_{95}\right)$ was $1 \mathrm{cp} / \mathrm{rxn}$ of the RTPCR. Validated LOD of whole procedure, including extraction, was $50 \mathrm{cp} / \mathrm{mL}$ of unprocessed sample using data obtained from nasopharyngeal/oropharyngeal samples.

\section{Results}

Stability of saliva specimens

To confirm the stability of saliva samples, we performed 36 serial tests on 8 primary SARS-CoV-2 positive saliva samples collected from patients 48 hours after their NPS tested positive. The data are summarized in Tables 1-3. Testing was randomized by different time intervals, the time of day, and the shifts of technicians. It includes repeated testing of two samples after $22 \mathrm{~h}$ (Table 2) and serial repeats of one sample (Table 3 ) with Ct value reporting.

All results confirmed a positive result after $22-25 \mathrm{~h}$ of the first test being conducted. Samples were stored refrigerated at 2-6खC between tests. 
Between May 13 and September 21, 2020, 431 tests on saliva samples were performed, and the results were compared with paired NPS RT-PCR test results. Using NPS RT-PCR as the reference, there were 104 PCR positive samples and 327 negative patients, including 125 pediatric (age 5-17 years (average 11.3 years)) samples. The observed RT-PCR positive results were divided into groups according to the number of days after the onset of symptoms: 0-14 days (22 patients); 15-30 days (52 patients); 31-70 days (20 patients) and 10 asymptomatic patients. The results of the comparison of the mentioned subgroups are presented in Table 4.

Sensitivity and specificity for the respective groups were: for $0-14$ days $90 \%(95 \% \mathrm{Cl} 68.3 \%-98.7 \%)$ and $100 \%(95 \% \mathrm{Cl}$ $22.4 \%-100 \%)$; for $15-30$ days $64.7 \%$ (95\% Cl 46.5\%-80.3\%) and 83.3\% (95\%Cl 58.9\%-96.4\%); for $31-70$ days $71.4 \%$ (95\% Cl 29.0\%-96.3\%) and 84.6\% (95\%Cl 54.6\%-98.1\%); for asymptomatic $71.4 \%$ (95\% Cl 29.0\%-96.3\%) and 66.7\% (95\% Cl 0.8\%-90.6\%). The mean Ct values for the groups were 33.9 for NPS and 33.8 for saliva (0-14 days), 34.8 for NPS and 34 for saliva (15-30 days), and 36.5 for NPS and 39 for saliva in the asymptomatic patient group.

\section{Pooling of saliva}

To evaluate the testing of pooled saliva samples, 37 pools were constituted. There were 15 pools of 5 samples (4 negatives +1 positive), 13 pools of 10 samples ( 9 negatives +1 positive), and 9 pools of 20 samples (19 negatives + 1 positive). The RT-PCR testing for each pool was repeated twice. The total number of measurements was 74 . All results were $100 \%$ positive.

When using pooling, the number of tests needed per sample was calculated as follows: the total number of tests needed to test all samples is divided by the total number of samples. For example, if 500 samples are being tested in pools of 10 , it means 50 tests are initially needed. With a positivity rate of $1 \%$, a maximum of five pools will contain a positive specimen (if each positive sample is in a different pool). The 50 samples from these five pools will have to be retested individually (each of the five positive pools contains 10 samples). Therefore, a total of 100 tests are needed to evaluate all 500 samples and the number of tests per sample is $100 / 500=0.2$.

The positivity rate in Latvia on September 23,2020 , was $0.5 \%$.

The approximate positivity rate at which the pooling of 5 samples becomes more efficient than the pooling of 10 samples is $3 \%$ (2-4\% depending on test price, laboratory load, tests per sample).

Field study

To evaluate the convenience of saliva pool testing by RT-PCR in field conditions, the town of Kuldiga (total population 10,352) with an ongoing outbreak of COVID-19 in a textile factory was selected. In collaboration with local authorities, 4,100 saliva self-sampling kits were distributed to inhabitants at a specially established distribution point. There were four persons dedicated to the distribution of the kits and four drivers to deliver the samples by car to the testing laboratory in Riga (150 km one way). During the study period, 3,660 saliva samples were collected (response rate $91.5 \%$ ), delivered to the laboratory, and tested in pools of 10 samples. There were a total of 366 pools. In the first round of testing 43 pools were found to be positive and samples from these pools were re-tested individually. The saliva samples from 44 patients were confirmed as positive by RT-PCR. Mean Ct values of pooled samples were $13 \%$ higher than individually tested $\mathrm{Ct}$ (31.6 versus 27.6 ). The positivity rate of the tested population was $1.2 \%$. In total 796 RT-PCR tests were performed. At the time of the sample collection, $68.2 \%(30 / 44)$ of patients did not report any symptoms on the questionnaire form. 
Nasopharyngeal swab tests and saliva tests were compared with the number of new COVID-19 cases. The findings illustrate that the second peak in new cases occurred 6-7 days after the initial peak. Such findings correspond with the mean incubation period of the SARS-CoV-2. The results reflect a decrease in new cases in the following observation period (Figure 1 Comparison of confirmed new cases with testing in field study).

Contactless self-service terminals and saliva testing on national level

In total, (between September 29, 2020 and April 10, 2021) 415673 RT-PCR tests of saliva were conducted. Tests were used for screening purpose of local population in selected municipalities, healthcare workers and other essential teams, social care centers, schools, pre-school groups, participants of special meetings, sport competitions and award ceremonies. Contactless self-service terminals were accepted in hospitals, factories and municipalities as an additional way to submit self-collected saliva for testing. The order-sample-result flow for contactless solution is represented Figure 2 Process Flow. Until April 10. 2021, 6 selfservice terminals have been installed. This option was used for 14294 saliva samples (3,4\% of all saliva samples). The total number of performed RT-PCR tests on saliva samples in our laboratory are presented in Table 5. Percentage of saliva samples used for testing inceased continuously month after month reaching $67 \%$ of all SARS-CoV-2 tests performed in our laboratory in March 2021.

\section{Discussion}

The findings of our study can be summarized as follows: (a) for the detection of SARS-CoV-2, saliva is a stable specimen with acceptable specificity and sensitivity at the early stages of infection; (b) saliva specimen is appropriate for pooling, with accurate diagnostic performance; (c) self-sampling of saliva was well accepted by the different groups of population and the new, automated, contactless terminal is the preferred option to increase the accessibility to testing.

Saliva has been identified as a reliable testing specimen for SARS-CoV-2 using the RT-PCR approach in several recent studies [7-9]. In the updated European Centre for Disease Prevention and Control (ECDC) recommendations, saliva is also mentioned as a convenient specimen for SARS-CoV-2 testing [10,11]. The FDA has approved methods for SARS-CoV-2 testing using saliva in several laboratories [12,13]. Nevertheless, saliva has been included in IFCC COVID-19 Guidelines on Molecular, Serological, and Biochemical / Haematological Testing as a promising sample type [14].

In addition, two recently published meta-analyses have concluded that self-administered saliva tests are on par with nose and throat swabs for detecting SARS-Cov-2 [15,16].

The high expression of ACE2 receptors in salivary gland cells is the main factor for virus affinity that could lead to active replication and transmission by saliva droplets expelled into the air during coughing or sneezing $[17,18]$.

It is essential to establish standardized sample collection procedures, safe logistics, and reliable testing methods that meet performance requirements. Our stability testing confirmed that saliva samples stayed equally positive up to $24 \mathrm{~h}$.

In the analytical context, saliva can have the same or even better performance than NPS [19]. It has been previously confirmed to be highly sensitive and specific at the early stage of infection 0-14 days after onset of symptoms and in asymptomatic cases [20]. Therefore, it is essential to take into consideration the relationship between the dynamics of viral load, Ct values, and the number of days after the onset of symptoms. As described in prior publications, the Ct value is important in determining the infectiousness of a patient sample. Ct values above 34 do 
not emit infectious virus particles, and values between 27-34 show low viability of the viral load. Samples with a Ct value of 13-17 show positive virus viability [21]. Ct values may vary depending on the different assays by up to 5 cycles for the same sample [22]. Variation also appears due to the quality of the specimen obtained and the different treatment methods used to prepare samples for testing [23]. As expected, we got some variation between the NPS and saliva sample types. In our pilot testing using 44 positive saliva samples we found slightly higher (13\%) Ct values in pools, compared to individual tests. Similar findings have been published by other researchers [24]. This observed slight difference still allows for the safe use of saliva pooling for surveillance purposes with sufficient diagnostic accuracy. Nevertheless, pooling strategies are described in the latest update of COVID-19 testing strategies and objectives published by the ECDC [11]. There is evidence of benefits from pooling in low prevalence countries with a low proportion of positive samples - up to $5 \%$. Recent publications indicate that for populations with a prevalence of less than $1 \%$ the testing of saliva pools of 10 or 20 samples is more beneficial, and our independent calculations also bear this out. Comparing the correlation between different pool sizes (usefulness and efficiency) with test positivity rate, we concluded that a pool size of 10 is more efficient than a pool size of 5 . The calculations are based on test price, reimbursement conditions, and the number of tests per sample (when using a pooling strategy) $[25,26]$. The pooling strategy for self-collected saliva samples is the optimal solution that saves resources and reduces the testing time [27]. In our real-life field test on a "perifocal" population, we successfully tested nearly a third of the citizens of the town of Kuldiga in three days. This allowed for fast identification of asymptomatic SARS-CoV-2 cases and those with mild symptoms to enable timely contact tracing and outbreak containment. The use of nasopharyngeal swabs in such a situation would have required more staff and time with possible patient compliance issues.

Additionally, improvements may reasonably be expected in terms of organizing the distribution of self-sampling kits to patients as well as the logistics of returning the kits to the laboratory that would further increase the usefulness of screening using a pool testing strategy. The contactless self-service terminals has shown a promising response to sample collection challenge, making preanalytical steps safer, more accessible and more convinient for selected groups of population. Self-testing kit distribution and collection points could also be further implemented for other dianostic purposes beside COVID-19 pandemia. The current capabilities allow further integration of urine and feces sample collection, based on the same process.

There were some limitations in our study: the size of the cohort of participants was limited, the selected laboratorydeveloped RT-PCR method for evaluation was used, also a lack of multicenter observation. Future studies extending the cohort are needed to confirm current findings and provide the implications in clinical practice.

In conclusion our findings confirm the stability of SARS-CoV-2 RNA in saliva, showing acceptable performance in terms of specificity and sensitivity at the early stages of infection, and the advantages of testing using a pooling strategy in a low prevalence population. Ct values and detected/missing gene information are favorable for the interpretation of the results from several aspects, e.g. epidemiological investigation, determination if the patient is infectious at the current stage, etc. Self-sampling makes the procedure faster, safer, and requires fewer resources. The targeted distribution of test kits among a population with a known outbreak significantly increased the positivity rate. Saliva pool testing on a large scale provides an additional tool to take timely measures and contain outbreaks.

\section{Declarations}

\section{Ethics approval and consent to participate}


The study was approved by the Ethics Committee of the Pauls Stradins Clinical University Hospital (record No 300720-18L).

Informed consent was obtained from all individual participants included in the study. Written informed consent was obtained from the parents of pediatric participants.

Consent for publication: Not applicable

Availability of data and material: The datasets generated during and analyzed during the current study are available from the corresponding author on reasonable request.

Competing interests: All authors declare that there are no conflicts of interest.

Funding: E.Gulbja laboratory

Partially funded by Ministry of Education and Science, Republic of Latvia. Funding number: VPP-COVID-2020/10008.

Authors' contributions: The conception and design of the study - Didzis Gavars; Oligonucleotide design and initial validation of RT-PCR - Dmitry Perminov; Validation of the whole method procedure and interpretation of the data Mikus Gavars and Zane Metla; Patient recruitment and data collection, drafting of the article - prof. Jana Pavare, Janis Stasulans, Justine Stana; Data analysis - Eriks Tauckels; Revising the article critically, final approval of the version to be submitted - Egils Gulbis and prof.Uga Dumpis.

\section{Acknowledgements}

We gratefully acknowledge all participants for their commitment to participate and their time. Special thanks to all trial team members in the E.Gulbja Laboratory for their dedication and work which made this study possible and Dr. A.Gramatniece for editorial help.

\section{References}

1. Rapid Risk Assessment: Coronavirus disease 2019 (COVID-19) in the EU/EEA and the UK- ninth update [Internet]. Eur. Cent. Dis. Prev. Control 202023 [cited 2020 16];doi: https://www.ecdc.europa.eu/en/publicationsdata/rapid-risk-assessment-coronavirus-disease-2019-covid-19-pandemic-ninth-update

2. Laboratory testing for 2019 novel coronavirus (2019-nCoV) in suspected human cases [Internet]. [cited 2020 16];doi: https://www.who.int/publications-detail-redirect/10665-331501

3. COVID-19: Overcoming supply shortages for diagnostic testing | McKinsey [Internet]. [cited 2020 16];doi: https://www.mckinsey.com/industries/pharmaceuticals-and-medical-products/our-insights/covid-19overcoming-supply-shortages-for-diagnostic-testing\#

4. Jeong HW, Kim S-M, Kim H-S, Kim Y-I, Kim JH, Cho JY, et al. Viable SARS-CoV-2 in various specimens from COVID-19 patients. Clin. Microbiol. Infect. 2020;26:1520-4. doi: 10.1016/j.cmi.2020.07.020

5. COVID-19 situation update for the EU/EEA and the UK, as of 16 November 2020 [Internet]. Eur. Cent. Dis. Prev. Control [cited 2020 16];doi: https://www.ecdc.europa.eu/en/cases-2019-ncov-eueea

6. Marty FM, Chen K, Verrill KA. How to Obtain a Nasopharyngeal Swab Specimen. N. Engl. J. Med. 2020 28;382:e76. doi: 10.1056/NEJMvcm2010260 
7. Fakheran O, Dehghannejad M, Khademi A. Saliva as a diagnostic specimen for detection of SARS-CoV-2 in suspected patients: a scoping review. Infect. Dis. Poverty 2020 22;9:100. doi: 10.1186/s40249-020-00728-w

8. Hamid H, Khurshid Z, Adanir N, Zafar MS, Zohaib S. COVID-19 Pandemic and Role of Human Saliva as a Testing Biofluid in Point-of-Care Technology. Eur. J. Dent. [Internet] 20203 [cited 2020 16];doi: http://www.thieme-connect.de/DOI/DOI?10.1055/s-0040-1713020doi: 10.1055/s-0040-1713020

9. Czumbel LM, Kiss S, Farkas N, Mandel I, Hegyi A, Nagy Á, et al. Saliva as a Candidate for COVID-19 Diagnostic Testing: A Meta-Analysis. Front. Med. 2020 4;7:465-465. doi: 10.3389/fmed.2020.00465

10. Objectives for COVID-19 testing in school settings - first update, 21 August 2020. Tech. Rep. 2020;4.

11. COVID-19 testing strategies and objectives [Internet]. Eur. Cent. Dis. Prev. Control 202018 [cited 2020 16];doi: https://www.ecdc.europa.eu/en/publications-data/covid-19-testing-strategies-and-objectives

12. Commissioner $\mathrm{O}$ of the. Coronavirus (COVID-19) Update: FDA Authorizes First Diagnostic Test Using At-Home Collection of Saliva Specimens [Internet]. FDA 20205 [cited 2020 16];doi: https://www.fda.gov/newsevents/press-announcements/coronavirus-covid-19-update-fda-authorizes-first-diagnostic-test-using-homecollection-saliva

13. Rutgers Launches Genetic Testing Service for New Coronavirus | Rutgers University [Internet]. [cited 2020 16];doi: https://www.rutgers.edu/news/rutgers-launches-genetic-testing-service-new-coronavirus

14. Bohn M, Mancini N, Loh P, Wang C-B, Grimmler M, Gramegna M, et al. IFCC interim guidelines on molecular testing of SARS-CoV-2 infection. Clin. Chem. Lab. Med. 2020 7; doi: 10.1515/cclm-2020-1412

15. Mayara Lisboa Bastos, Sara Perlman-Arrow, Dick Menzies, Jonathon R. Campbell, et al. The Sensitivity and Costs of Testing for SARS-CoV-2 Infection With Saliva Versus Nasopharyngeal Swabs: A Systematic Review and Meta-analysis. Ann Intern Med. 2021 Jan 12: M20-6569. Published online 2021 Jan 12. doi: 10.7326/M206569 PMCID: PMC7822569

16. Butler-Laporte G, Lawandi A, Schiller I, Yao M, Dendukuri N, McDonald EG, Lee TC. Comparison of Saliva and Nasopharyngeal Swab Nucleic Acid Amplification Testing for Detection of SARS-CoV-2: A Systematic Review and Meta-analysis. JAMA Intern Med. 2021 Mar 1;181(3):353-360. doi: 10.1001/jamainternmed.2020.8876. Erratum in: doi: 10.1001/jamainternmed.2021.0245. PMID: 33449069; PMCID: PMC7811189.

17. Liu L, Wei Q, Alvarez X, Wang H, Du Y, Zhu H, et al. Epithelial Cells Lining Salivary Gland Ducts Are Early Target Cells of Severe Acute Respiratory Syndrome Coronavirus Infection in the Upper Respiratory Tracts of Rhesus Macaques. J. Virol. 2011 15;85:4025-30. doi: 10.1128/JVI.02292-10

18. Xu J, Li Y, Gan F, Du Y, Yao Y. Salivary Glands: Potential Reservoirs for COVID-19 Asymptomatic Infection. J. Dent. Res. 2020;99:989. doi: 10.1177/0022034520918518

19. Wyllie AL, Fournier J, Casanovas-Massana A, Campbell M, Tokuyama M, Vijayakumar P, et al. Saliva or Nasopharyngeal Swab Specimens for Detection of SARS-CoV-2. N Engl J Med 2020;4.

20. Zhang W, Du R-H, Li B, Zheng X-S, Yang X-L, Hu B, et al. Molecular and serological investigation of 2019-nCoV infected patients: implication of multiple shedding routes. Emerg. Microbes Infect. 2020 17;9:386-9. doi: 10.1080/22221751.2020.1729071

21. La Scola B, Le Bideau M, Andreani J, Hoang VT, Grimaldier C, Colson P, et al. Viral RNA load as determined by cell culture as a management tool for discharge of SARS-CoV-2 patients from infectious disease wards. Eur. J. Clin. Microbiol. Infect. Dis. 2020 27;1-3. doi: 10.1007/s10096-020-03913-9

22. Nalla AK, Casto AM, Huang M-LW, Perchetti GA, Sampoleo R, Shrestha L, et al. Comparative Performance of SARS-CoV-2 Detection Assays Using Seven Different Primer-Probe Sets and One Assay Kit. J. Clin. Microbiol. 2020;58. doi: 10.1128/JCM.00557-20 
23. Rodino KG, Espy MJ, Buckwalter SP, Walchak RC, Germer JJ, Fernholz E, et al. Evaluation of Saline, PhosphateBuffered Saline, and Minimum Essential Medium as Potential Alternatives to Viral Transport Media for SARSCoV-2 Testing. J. Clin. Microbiol. 2020 26;58:e00590-20. doi: 10.1128/JCM.00590-20

24. Lohse S, Pfuhl T, Berkó-Göttel B, Rissland J, Geißler T, Gärtner B, et al. Pooling of samples for testing for SARSCoV-2 in asymptomatic people. Lancet Infect. Dis. 2020 1;20:1231-2. doi: 10.1016/S1473-3099(20)30362-5

25. Regen F, Eren N, Heuser I, Hellmann-Regen J. A simple approach to optimum pool size for pooled SARS-CoV-2 testing. Int. J. Infect. Dis. 2020 1;100:324-6. doi: 10.1016/j.ijid.2020.08.063

26. Mutesa L, Ndishimye P, Butera Y, Souopgui J, Uwineza A, Rutayisire R, et al. A pooled testing strategy for identifying SARS-CoV-2 at low prevalence. Nature 2020 21;1-8. doi: 10.1038/s41586-020-2885-5

27. Fogarty A, Joseph A, Shaw D. Pooled saliva samples for COVID-19 surveillance programme. Lancet Respir. Med. 2020;8:1078-80. doi: 10.1016/S2213-2600(20)30444-6

\section{Tables}

Table 1 Run No. 1 on saliva stability measurements of 5 samples collected $2-4$ h before the first testing

\begin{tabular}{|lllll|}
\hline & $\mathbf{0}$ & after $8 \mathrm{~h}$ & after 24h & after 25h \\
\hline & 1st 14:00 & 2nd 22:00 & 3rd 14:00 & 4th 15:00 \\
\hline 1 & Positive & Positive & Positive & Positive \\
\hline 2 & Positive & Positive & Positive & Positive \\
\hline 3 & Positive & W-Positive & Positive & W-Positive \\
\hline 4 & Positive & Positive & Positive & No sample left \\
\hline 5 & Positive & W-Positive & Positive & W-Positive \\
\hline
\end{tabular}

Abbreviations: W-Positive - weak positive result, $\mathrm{h}$ - hours

Table 2 Run No. 2 on saliva stability serial measurements of two samples collected 2-4h before first testing

\begin{tabular}{|c|c|c|c|c|}
\hline & 0 & after $12 \mathrm{~h}$ & after $22 \mathrm{~h}$ & after $22 \mathrm{~h}$ rep. \\
\hline & 1 st $12: 00$ & 2nd $00: 00$ & 3rd 10:00 & 4th $10: 00$ \\
\hline 6 & W- Positive & Positive & Positive & Positive \\
\hline Ct & 35 & 36 & 37 & 37 \\
\hline 7 & Positive & Positive & Positive & Positive \\
\hline Ct & 32 & 33 & 30 & 31 \\
\hline
\end{tabular}

Abbreviations: W-Positive - weak positive result, rep. - repeats, $\mathrm{h}$ - hours

Table 3 Run No. 3 on saliva repeatability measurements of one sample collected 2 - 4 h before the first testing with indicated Ct values 


\begin{tabular}{|lllll|}
\hline & $\mathbf{0}$ & after $3 \mathrm{~h}$ & after 12h & after $24 \mathrm{~h}$ \\
\hline 8 & Pst 17:00 & 2nd 14:00 & 3rd 02:00 & 4th 17:00 \\
\hline Ct & 34 & 30 & 33 & 35 \\
\hline 8 rep. & Positive & Positive & Positive & Positive \\
\hline Ct & 34 & 27 & 31 & 35 \\
\hline
\end{tabular}

Abbreviations: rep. - repeats, $\mathrm{h}$ - hours

Table 4 Saliva samples compared to the results of nasopharyngeal/ oropharyngeal swabs

\begin{tabular}{|c|c|c|c|c|c|c|c|c|c|}
\hline \multirow{2}{*}{\multicolumn{2}{|c|}{$\begin{array}{l}\text { Days after the } \\
\text { start of symptoms }\end{array}$}} & \multicolumn{8}{|c|}{ NPS } \\
\hline & & \multicolumn{2}{|l|}{$0-14$} & \multicolumn{2}{|l|}{$15-30$} & \multicolumn{2}{|l|}{$31-70$} & \multicolumn{2}{|c|}{ Asymptomatic } \\
\hline RT-PCF & & Positive & Negative & Positive & Negative & Positive & Negative & Positive & Negative \\
\hline \multirow[t]{2}{*}{ Saliva } & Positive & 18 & 0 & 22 & 3 & 5 & 2 & 5 & 1 \\
\hline & Negative & 2 & 2 & 12 & 15 & 2 & 11 & 2 & 2 \\
\hline \multicolumn{2}{|c|}{ Sensitivity \% } & \multicolumn{2}{|l|}{90} & \multicolumn{2}{|l|}{64.7} & \multicolumn{2}{|l|}{71.4} & \multicolumn{2}{|l|}{71.4} \\
\hline \multicolumn{2}{|c|}{ Specificity \% } & \multicolumn{2}{|l|}{100} & \multicolumn{2}{|l|}{83.3} & \multicolumn{2}{|l|}{84.6} & \multicolumn{2}{|l|}{66.7} \\
\hline
\end{tabular}

Abbreviations: NPS - nasopharyngeal/ oropharyngeal swabs, RT-PCR - real-time polymerase chain reaction

Table 5 Results of saliva testing by RT-PCR in E.Gulbja laboratory between September 29, 2020 and April 10, 2021 


\begin{tabular}{|c|c|c|c|c|c|c|c|c|}
\hline Month & $\begin{array}{l}\text { No of } \\
\text { Saliva } \\
\text { samples }\end{array}$ & $\begin{array}{l}\text { No of } \\
\text { Positive } \\
\text { results } \\
\text { in } \\
\text { Saliva }\end{array}$ & $\begin{array}{l}\text { Positivity } \\
\%\end{array}$ & $\begin{array}{l}\text { Saliva } \\
\text { samples } \\
\text { from Self- } \\
\text { sampling } \\
\text { terminals } \\
\text { (SST) }\end{array}$ & $\begin{array}{l}\text { No of } \\
\text { Positive } \\
\text { results } \\
\text { of Saliva } \\
\text { from } \\
\text { (SST) }\end{array}$ & $\begin{array}{l}\text { Positivity } \\
\%\end{array}$ & $\begin{array}{l}\text { Saliva/NPS } \\
\text { samples \% }\end{array}$ & $\begin{array}{l}\text { SST/Saliva } \\
\text { total } \\
\text { samples \% }\end{array}$ \\
\hline $\begin{array}{l}2020- \\
09\end{array}$ & 2678 & 46 & $1.7 \%$ & 0 & 0 & & $8.3 \%$ & $0.0 \%$ \\
\hline $\begin{array}{l}2020- \\
10\end{array}$ & 17756 & 439 & $2.5 \%$ & 0 & 0 & & $27.8 \%$ & $0.0 \%$ \\
\hline $\begin{array}{l}2020- \\
11\end{array}$ & 39370 & 1152 & $2.9 \%$ & 0 & 0 & & $46.8 \%$ & $0.0 \%$ \\
\hline $\begin{array}{l}2020- \\
12\end{array}$ & 71285 & 2844 & $4.0 \%$ & 1855 & 100 & $5.4 \%$ & $59.3 \%$ & $2.6 \%$ \\
\hline $\begin{array}{l}2021- \\
01\end{array}$ & 78269 & 2545 & $3.3 \%$ & 4890 & 204 & $4.2 \%$ & $59.2 \%$ & $6.2 \%$ \\
\hline $\begin{array}{l}2021- \\
02\end{array}$ & 71067 & 1357 & $1.9 \%$ & 3836 & 68 & $1.8 \%$ & $60.8 \%$ & $5.4 \%$ \\
\hline $\begin{array}{l}2021- \\
03\end{array}$ & 104316 & 845 & $0.8 \%$ & 3045 & 59 & $1.9 \%$ & $67.0 \%$ & $2.9 \%$ \\
\hline $\begin{array}{l}2021- \\
04\end{array}$ & 30932 & 249 & $0.8 \%$ & 668 & 21 & $3.1 \%$ & $68.1 \%$ & $2.2 \%$ \\
\hline
\end{tabular}

Abbreviations: SST- Contactless self-sampling terminal, NPS - nasopharyngeal/ oropharyngeal swabs, RT-PCR - realtime polymerase chain reaction

Figures 


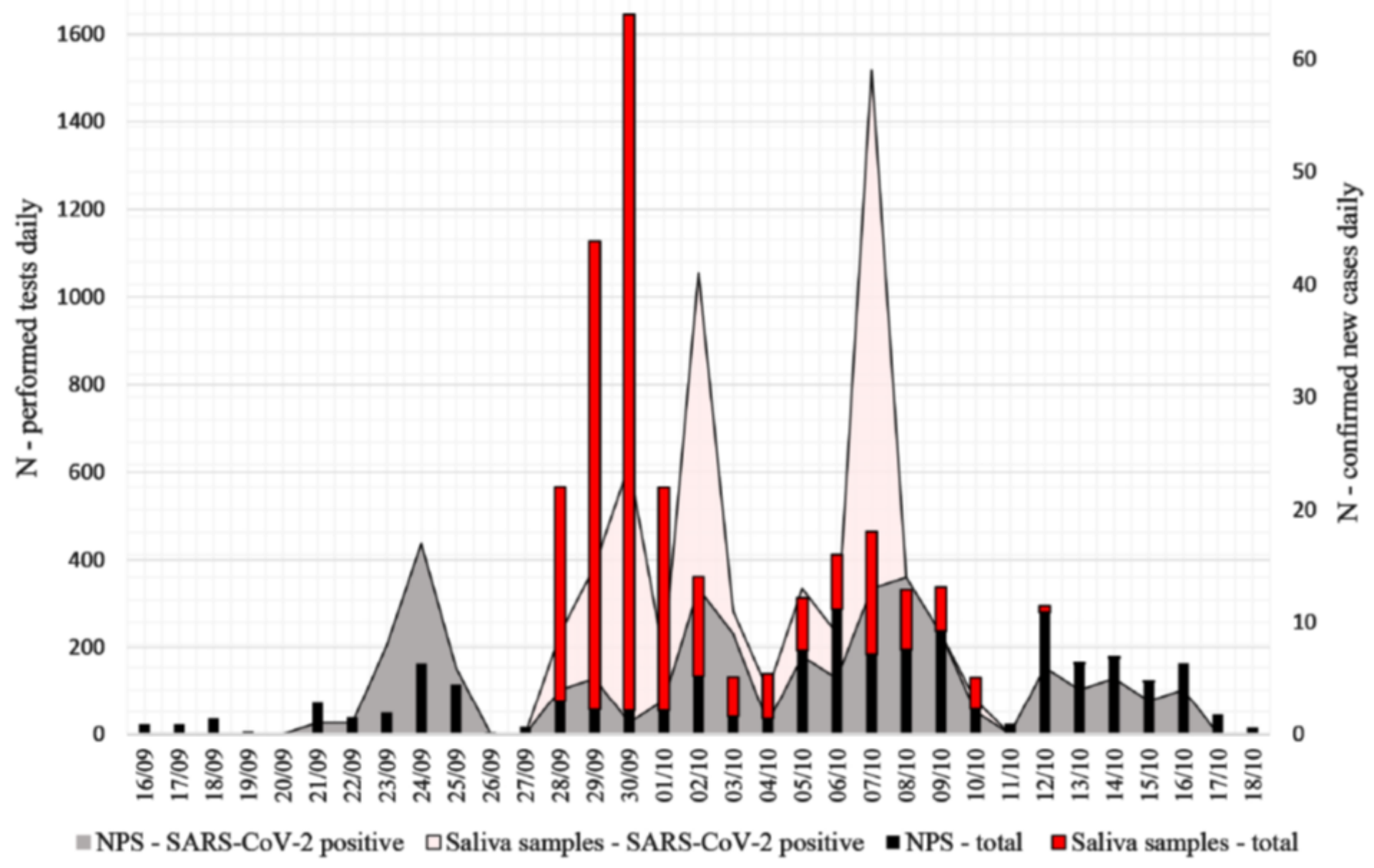

Figure 1

Comparison of confirmed new cases with testing in field study 


\section{Process Flow}

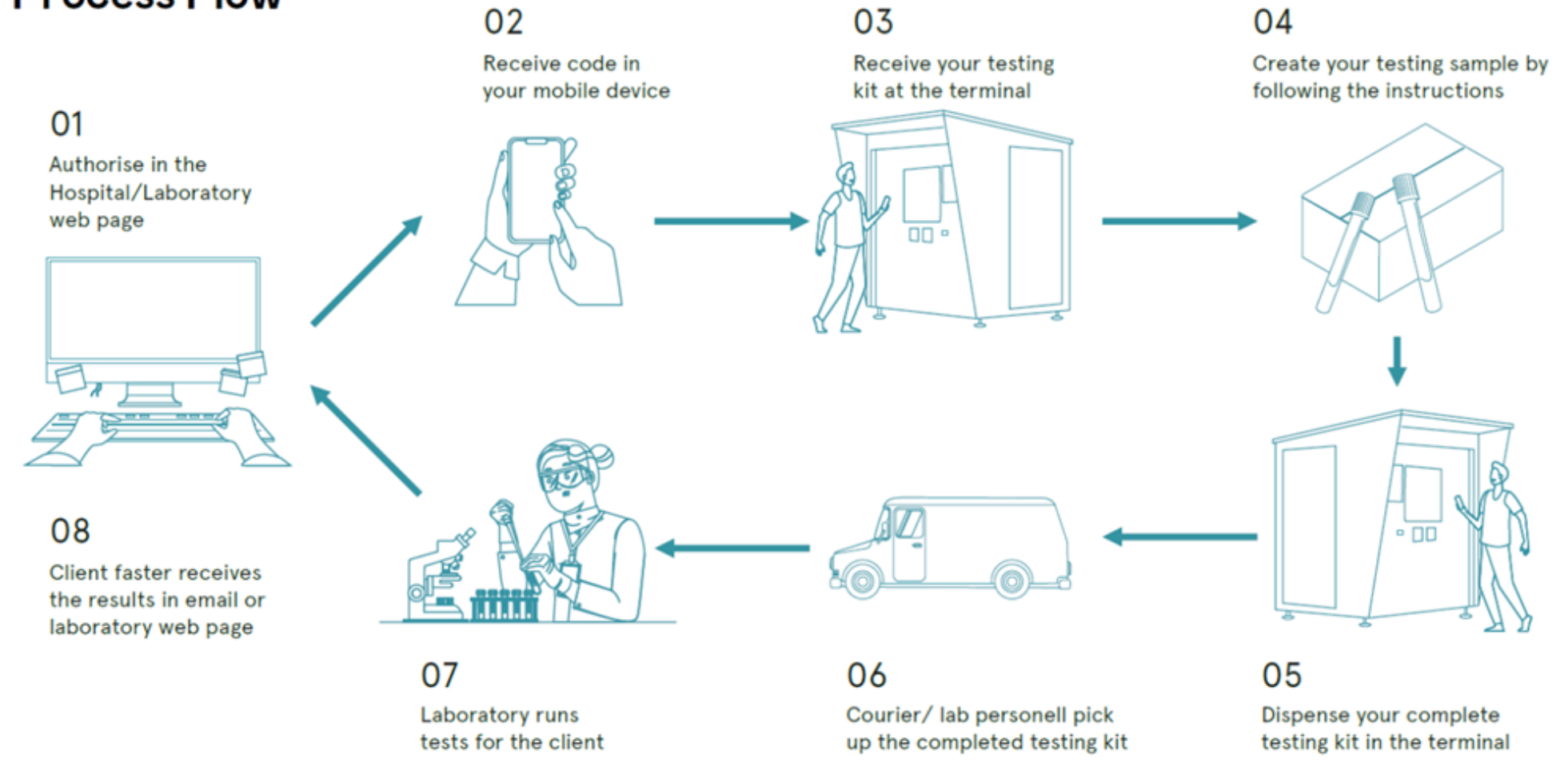

\section{Figure 2}

Process flow 